\title{
RECRUTAMENTO DE TRABALHADORES MIGRANTES NA CANA-DE-AÇÚCAR NO ESTADO DE PERNAMBUCO
}

\author{
Marilda Aparecida de Menezes*
}

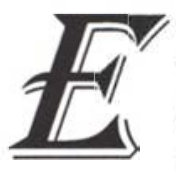

ste artigo trata do recrutamento de trabalhadores migrantes sazonais na plantation açucareira no Estado de Pernambuco, na região chamados "corumbas". Toma-se como estudo de caso os camponeses provenientes da Região Agreste do Estado da Paraíba, que migram desde princípios do século XX, para trabalhar em diversas atividades em engenhos e usinas de cana de açúcar na Zona da Mata, norte do Estado de Pernambuco. Foram selecionados na região de origem, o município de Fagundes, no Estado da Paraíba e a Usina São José, no município de Igarassu, Estado de Pernambuco. A literatura geralmente explica que a contratação de camponeses-trabalhadores migrantes (Menezes, 1997) resulta de diferenças entre a quantidade de trabalho requerida em cada uma das fases do ciclo agrícola. Durante a colheita, demanda-se um número grande de trabalhadores, em comparação com as fases de cultivo e limpeza da cana-de-açúcar, e esse trabalho não poderia ser suprido, apenas, com a mão-de-obra local. Embora essa explicação seja verdadeira, o recrutamento intensivo dos camponesestrabalhadores migrantes, após um período no qual se verifica o seu declínio, também se explica pela racionalização e controle político da força de trabalho, para alcançar altos níveis de produtividade e lucratividade (Novaes, 1993, p.115).
Com relação à plantation açucareira no Estado da Paraíba, alguns autores já mostraram que houve um aumento do número de trabalhadores migrantes sazonais durante a década de 1980 e 1990 , que se explica pelas ações sindicais e pelas transformações na agricultura na Região Agreste (Moreira, 1995, p.212 213). A estratégia de contratar trabalhadores do Agreste e do Sertão como uma resposta ao aumento da organização sindical não é apenas encontrada nos estados do Nordeste do Brasil (Novaes, 1993), mas é, também, recorrente em outros países produtores de cana-de-açúcar, além de outros produtos agrícolas. Mencionaria três exemplos. Primeiro, o caso da República Dominicana na América Central, analisado por Baud (1992); segundo, o caso dos trabalhadores migrantes na cana-de-açúcar na India, analisado por Breman (1985); e, finalmente, trabalhadores agrícolas migrantes nos Estados Unidos, analisado por Burawoy (1976). O exemplo dos Estados Unidos é muito mais complexo que a migração sazonal interna no Nordeste do Brasil, porque envolve a questão da imigração ilegal, que tem sérias consequências para as condições e direitos trabalhistas.

Para Breman (1985), o funcionamento do mercado de trabalho explicase mais por fatores de controle político do que pelo preço do trabalho: "trabalhadores migrantes são mais baratos, mas isto é uma vantagem casual e não a razão principal pela qual eles são preferidos (...) O rebaixamento dos níveis salariais é tanto um efeito quanto um objetivo do excedente de força de trabaIho" (Breman, 1985, p. 335).

No tocante aos trabalhadores migrantes agrícolas nos Estados Unidos, Burawoy (1976, p.1072) afirma que quando o trabalho doméstico demonstra capacidade de organização, ele tem sido ou deslocado pelo trabalho migrante - externo ou interno - ou violentamente reprimido. Os fazendeiros têm grande controle sobre os "trabalhadores migrantes", porque eles estão continuamente disponíveis para todos os tipos de tarefas, desde bem cedo da manhã, até bem tarde da noite. Além do mais, eles são diligentes, sensatos, corretos e dóceis (Breman, 1985). Baud expressa esse mesmo ponto de vista, com referência aos migrantes haitianos, que migram para a República Dominicana, afirma que é difícil controlar nativos e, em muitas partes do mundo, o trabalho é recrutado de regiões distantes, mesmo que exista uma reserva local.

No caso da Região Nordeste, os camponeses-trabalhadores migrantes são preferidos pelos gerentes, pois predomina o discurso de que eles são mais submissos ao controle da usina (Novaes, 1993). Desde o momento do recrutamento até o espaço da moradia em alojamentos, os camponeses-trabalhadores migrantes são circundados por táticas políticas de controle do trabalho, que 
são contracenadas por suas redes sociais e práticas de resistência.

A contratação dos camponeses-trabalhadores migrantes é implementada através de um sistema de recrutamento, no qual a pessoa central é o arregimentador, uma espécie de empreiteiro $^{1}$, que é responsável por coletar as carteiras de trabalho dos migrantes e trazê-las para a usina. Segundo definição de um dos gerentes da Usina São José, o arregimentador "faz a ligação entre capital e trabalho". Geralmente, é uma pessoa do local de origem dos migrantes e atua como um intermediário entre a usina e os trabalhadores, no que diz respeito ao recrutamento, trabalho e vida nos alojamentos. Em geral é um trabalhador migrante que conseguiu ganhar a confiança dos gerentes da usina e, também, é respeitado entre os seus colegas. Os escolhidos para esta função são considerados "bons trabalhadores", classificação que identifica aqueles que trabalham arduamente, não reclamam, nem reivindicam e aceitam as condições de trabalho e vida que lhes são impostas. Como é responsável pelos documentos dos trabalhadores, tem que ser uma pessoa alfabetizada, o que exclui a maioria dos trabalhadores migrantes. Outro critério comum para selecionar arregimentadores são as relações de parentesco; a usina São José teve três arregimentadores, desde o início do recrutamento em Fagundes, em 1978. O primeiro foi um cunhado de um cabo da usina, ele foi substituído por um outro paraibano, considerado pelos seus colegas um puxa-saco do patrão. Esse segundo arregimentador foi substituído por seu irmão, que justifica ter atendido ao pedido do gerente da usina, para que ele continuasse a recrutar trabalhadores. Ele assumiu essa posição em 1993 e continuou até a safra de 1996-7. Na usina Matari, o filho do arregimentador assumiu a posição de seu pai.

Como o arregimentador procede da área dos trabalhadores, ele está envolvido em relações pessoais, de amizade ou parentesco. Essas relações sociais têm sido definidas por alguns autores como uma combinação entre neopatronagem e solidariedade (Breman, 1985 , p.355). A posição social do arregimentador é similar ao mukadame descrito por Breman (1985), para o caso de "trabalhadores migrantes" da canade-açúcar na região Gujarat do Sul, na Índia. Como os mukadames, os arregimentadores são profissionais do recrutamento, a maioria trabalha com sua turma, ganhando o mesmo salário, mas tem um tratamento preferencial, ganhando pequenos agrados como cigarros ou chá (Breman, 1985). Na região estudada, o arregimentador pode ou não trabalhar com sua turma, e, além de seu salário, recebe uma porcentagem de $3 \%$ ou $4 \%$ da renda dos trabalhadores de sua turma. Esse sistema tem como objetivo motivá-lo a trazer "bons trabalhadores", aqueles que têm alta produtividade e tendem a aceitar as condições de trabalho impostas.

A posição do arregimentador é uma nova versão do empreiteiro que foi largamente utilizado pelos usineiros, durante as décadas de 1960 e 1970 . O empreiteiro é um intermediário que contrata a turma de trabalhadores para realizar uma determinada tarefa, sem, no entanto, estabelecer um contrato formal de trabalho. Como Schaffner diz:

"Os intermediários protegiam os patrões das obrigações de seguridade social e também eram capazes de se livrarem de obrigações trabalhistas porque seu tratamento no ETR (Estatuto do Trabalhador Rural) era ambíguo. O uso de intermediários foi drasticamente reduzido depois de uma onda de greves em 1979; mas ainda assim, no censo demográfico de 1980 constava que $16 \%$ dos trabalhadores agrícolas temporários no estado de Pernambuco trabalhavam com intermediários"3.

A diferença principal entre o arregimentador e o empreiteiro é em relação ao contrato de trabalho, os trabalhadores empregados pelo empreiteiro, geralmente, não têm contrato legal, enquanto os agenciados pelo arregimentador são contratados formalmente pela usina. Os sindicatos, no Estado de Pernambuco, travaram uma luta persistente contra a existência dos empreiteiros na contratação de trabalhadores, pois representava um mecanismo de negação dos direitos trabalhistas e conseguiram alterar essa prática. No entanto, ocasionalmente, casos de contratação ilegal são denunciados, e os sindicatos têm que empreender novas ações contra as usinas. A necessidade de recrutar "bons trabalhadores", que poderiam garantir a finalização da safra da cana-de-açúcar fez com que os usineiros implementassem a nova versão dos empreiteiros, os arregimentadores. Embora a imagem dos arregimentadores não seja associada ao trabalho clandestino, eles reproduzem, parcialmente, a posição social dos empreiteiros, especialmente quanto à sua função de disciplinarização dos trabalhadores, para garantir alta produtividade e obediência. A definição de Oliveira sobre os empreiteiros também é apropriada para os arregimentadores:

"A experiência na atividade açucareira é fator importante no exercício da empreitada porque faz parte do sucesso da intermediação a escolha de bons trabalhadores para garantir uma produção significativa e consequentemente uma boa comissão" (Oliveira, 1986, p.43).

É difícil identificar qual a categoria sob a qual é formalizado o contrato do arregimentador com a usina, bem como a forma de pagamento. Todos os três grupos entrevistados - trabalhadores, arregimentadores e gerentes de usina expressaram diferentes visões sobre a posição e função dos arregimentadores. Em relação ao status legal, alguns informam que o arregimentador é registrado como um trabalhador rural, enquanto para outros é como cabo, recebendo, aproximadamente, um salário três vezes maior que a média dos trabalhadores rurais. Os gerentes da usina declararam que ele é um trabalhador rural cujas funções são as mesmas que os demais 
trabalhadores de sua turma.

As atribuições do arregimentador podem variar durante o período que está trabalhando na usina e também há diferenciações entre as usinas. Por exemplo, o arregimentador que trabalhou para a Usina São José, entre 1985 e 1994, não trabalhou no campo, nos últimos três anos de seu contrato; seu irmão, que assumiu essa posição em 1994, trabalhava no campo, juntamente com sua turma. Na Usina Maravilha, o arregimentador geralmente não trabalhava no campo, mas era responsável pela supervisão dos seus trabalhadores. Apesar das indefinições que circundam a posição social do arregimentador, ele representa uma nova versão dos empreiteiros ${ }^{4}$. Ele permanece a pessoa chave no recrutamento e controle dos trabalhadores temporários, seja daqueles que procedem da região canavieira, de Pernambuco ou Paraíba, ou de camponeses-trabalhadores migrantes que vêm do Agreste e Sertão.

\section{RECBUTAMENTO ATRAV S DE REDES SOCHAIS}

O recrutamento é o primeiro passo para criar uma força de trabalho disciplinada e passiva e as redes sociais (Mayer, 1964 e Harries, 1994), formadas por parentesco e relações de amizade são os canais através dos quais o arregimentador seleciona os bons trabalhadores. De outro lado, as redes são, também, o espaço onde os trabalhadores trocam opiniões e informações sobre uma diversidade de aspectos relacionados à plantation açucareira e praticam formas de resistência espontâneas, individuais ou coletivas.

$O$ recrutamento de trabalhadores migrantes através de relações de parentesco, vizinhança e amizade também traz alguns conflitos dentro da comunidade de origem. Sendo o arregimentador um trabalhador migrante que conseguiu ascender socialmente, desperta nos outros o desejo de conquistar essa posição, o que causa uma certa competição entre os que se julgam capazes de se tornarem um arregimentador. Durante os dezesseis anos em que a Usina São José recrutou trabalhadores de Fagundes, alguns incidentes aconteceram que mostram os conflitos gerados pela posição superior do arregimentador em relação aos seus conterrâneos, parentes, vizinhos e amigos. O primeiro arregimentador, que trabalhou de 1979 a 1984 , perdeu sua posição para outro, que assumiu até 1993. Ambos são vizinhos e até a data do trabalho de campo, 1995 e 1996, eles não se conversavam; estórias diversas são narradas sobre a passagem de um arregimentador para outro, mas a nebulosidade em torno desse assunto começou a se dissipar um pouco quando a esposa do primeiro arregimentador contou que o segundo havia inventado fofocas sobre seu marido para os gerentes da usina, de modo que ele acabou sendo demitido.

Um dos entrevistados queria selecionar migrantes, conjuntamente com o arregimentador que trabalhou para a Usina São José, de 1984 até 1993. Ambos eram vizinhos e compadres e apesar dos laços de parentesco, o arregimentador não aceitou a parceira no recrutamento. A cada arregimentador é atribuído um número de trabalhadores para ser contratado, um mínimo, em geral, de 50 por turma. Um mês, aproximadamente, antes do começo da safra, a notícia sobre o recrutamento da usina difunde-se por toda a área, através da transmissão oral. Arregimentadores e gerentes da usina começam a chegar nos locais de procedência dos migrantes, para selecioná-los para a safra e são vistos por todas as partes do município, coletando carteiras de trabalho.

As redes informais entre os trabalhadores atuam como o veículo mais eficiente para agregar trabalhadores e trocar informações sobre as usinas. A feira local, que acontece todos os sábados, é, tradicionalmente, um lugar de encontro. Pessoas vêm de todos os distritos e sítios para fazer a feira semanal, ir ao mé- dico, visitar parentes e amigos, e resolver outras questões sociais. Ela é um lugar privilegiado, onde as pessoas se encontram e trocam informações sobre as usinas. Durante o trabalho de campo, dediquei a maioria das manhãs do sábado para circular pela feira e encontrar trabalhadores, arregimentadores e gerentes da usina. É parte do cenário da feira ver pequenos grupos de homens conversando, trocando informações, discutindo e construindo opiniões e visões sobre o trabalho e a vida nas usinas que recrutam trabalhadores no município. Essas redes informais têm se constituído como um espaço de comunicação importante dos camponeses- trabalhadores migrantes, nelas se produzem e circulam não apenas informações sobre o recrutamento, mas, também, sobre as condições de trabalho e moradia oferecidas pelas usinas, representações sobre as formas dos administradores e cabos tratarem os trabalhadores, bem como da atuação do sindicato.

Alguns eventos mostram que as redes sociais informais permitem a emergência de práticas individuais ou coletivas de resistência, destaco como exemplo dois deles. Em 1987, um gerente de usina que trabalhava para a Usina São José mudou de emprego, indo trabalhar numa usina no município de Baía Formosa, no Estado do Rio Grande do Norte; comentava-se que ele era um chefe carrasco, que maltratava os trabalhadores. Um dia, ele veio a Fagundes em busca de trabalhadores para a usina na qual estava trabalhando. Em torno de 50 trabalhadores decidiram ir, mas alguém divulgou a informação de que, durante o tempo em que trabalhou na Usina São José, esse gerente foi bruto e cruel. Um trabalhador descreveu o ocorrido em detalhe:

“Eu vi um caminhão grande e ele dizendo: eu sou de Baia Formosa, conheço o pessoal de Fagundes, um pessoal trabalhador. Eu digo: este é Dr.Eraque, isto é ele mesmo. Ele meio careca, meio calvo, meio baixo. O carro tava cheio de gente pra ele levar pra 
Baia Formosa, tava cheio. Aqui o cabra disse: aquele miserável ali foi o que cortou o dia da gente na usina S.José. Este cabeça chata aí, foi ele mesmo. Foi ele mesmo, este é Dr.Eraque, é ele. Aí rapaz, vão trabalhar de graça?! Por que rapaz? Porque na São José ele cortou o dia de todo mundo lá, 200 homens ele cortou. É este miserável e assim e aí começou a descer do carro, todo mundo descendo do carro, descendo... ai quando foi com pouco ele olhou assim e disse: oxente, cadê o pessoal que tava aqui. $O$ pessoal foi embora, porque $o$ senhor faz o trabalhador de escravo, cortou o dia dos trabalhador. Ele disse: quem foi que disse isto a vocês? Quem tava trabalhando la é quem disse, doutor. Ele pegou o carro pequeno, baixou a cabecinha, e nunca mais botou a cara aqui em Fagundes, nunca mais". (Oswaldo)

O gerente ficou sem nenhum trabalhador para levar à usina, e os migrantes provaram que a sua experiência em usinas da Mata Norte do Estado de Pernambuco tornou-se um recurso cultural importante para avaliar e reagir a situações de outras usinas. Neste caso, o que mais amedrontou os trabalhadores foi que a usina para onde estavam sendo levados era desconhecida na área, eles nem sequer lembram o nome. Um incidente similar aconteceu durante o recrutamento para a safra de 1995 e 1996. Além do arregimentador do local que trabalhava para a Usina São José, um segundo arregimentador de fora da localidade veio a Fagundes para selecionar trabalhadores. Como ele era desconhecido no município, houve muito rumor, desconfiança, interrogações sobre quem ele era e para qual engenho levaria os migrantes. Alguns trabalhadores até me cercaram, tentando encontrar alguma informação sobre ele, porque muitos já me tomavam em confiança e sabiam que tinha contatos com os arregimentadores e gerentes da usina. Este arregimentador "desconhecido" foi ajudado por duas pessoas do local para coletar as carteiras de trabalho para ele, porém, esses "subarregimentadores" também estavam confusos sobre qual era a usina e local para onde os migrantes seriam levados. Após terem coletado 70 carteiras de trabalho, os trabalhadores começaram a pedir seus documentos de volta e, rapidamente, os arregimentadores já não tinham sequer uma única carteira de trabalho em suas mãos. Alguns contaram que houve rumor e suspeita de que o arregimentador os levaria para o Estado do Maranhão, a 700 km do município, o que tornou os trabalhadores ansiosos e inseguros, pois temiam sobre a possibilidade de serem levados para locais desconhecidos, mediados por pessoas que não conheciam e não tinham referências pessoais.

Após a coleta das carteiras, o arregimentador leva os documentos para a usina ou o gerente da usina vem ao local para coletá-los. O processo de seleção dos trabalhadores obedece aos seguintes critérios:

1) Idade: os gerentes de usina têm uma preferência por pessoas jovens, entre 18 e 40 anos. Entretanto, isto não significa que todos os trabalhadores acima de 40 anos serão excluídos, pois este critério é combinado com outros fatores que são parte do processo de seleção.

2) Produtividade: Até recentemente, as usinas não tinham um registro sistemático dos níveis de produtividade dos trabalhadores, mas, em 1995-6, elas já começavam a ter registros anuais de cada trabalhador de modo a subsidiar o processo de seleção na safra seguinte.

3) Comportamento: Aqueles considerados "mal comportados" não serão contratados novamente. É geralmente o arregimentador e o cabo que comunicam à administração da usina sobre os 'mal e bem comportados'. O rótulo de "mal" será aplicado para trabalhadores que rejeitam obedecer as ordens dos chefes, em termos de cumprimento de atividades e horas de trabalho, que discutem com os chefes, discordam ou reclamam sobre o peso da cana ou faltam ao trabalho. No caso de trabalhadores migrantes isto também inclui "mau comportamento" no alojamento, ou durante o tempo de lazer.

4) Direitos trabalhistas: Trabalhadores que colocaram ação na justiça contra a usina não serão mais contratados. Eles são bem conscientes desta ameaça e, quando decidem tomar tal atitude, já se preparam para procurar emprego em outras usinas ou outros locais.

5) Abandono do contrato de safra: os trabalhadores migrantes são, em geral, contratados no início da safra, em setembro, sob o regulamento do contrato de safra, que estabelece que o trabalhador tem que cumprir o contrato até o final da safra. Entretanto, muitos decidem romper com o contrato ou, simplesmente, abandonar o emprego, devido às condições de exploração do trabalho.

6) Exame médico.

Estes critérios estão relacionados à racionalização dos métodos de trabalho, assim como ao controle da produção e produtividade. Um dos principais objetivos dos gerentes da usina é incrementar os níveis de produtividade de modo a reduzir o número de trabalhadores necessário nas várias etapas do processo produtivo. Para esse propósito, algumas usinas têm implementado um programa de treinamento para gerentes, chefes e trabalhadores. Os gerentes são enviados para usinas modernizadas no Estado de São Paulo e até para outros países, como por exemplo, África do Sul, onde os trabalhadores recebem treinamento que os motiva a produzir mais e melhorar seus métodos de trabalho. $\mathrm{O}$ engenheiro responsável pela implementação dos novos métodos de trabalho informou que o principal objetivo do treinamento é "mudar a cultura dos trabalhadores", o que significa motivá-los para produzir mais do que uma "tarefa", medida que regulamenta a quantidade mínima produzida num dia de trabalho. Como Breman (1985, p.261) afirma, o processo de racionalização social, que implica uso mais instrumental do trabalho, facilita a introdução de novas tecnologias e do 
gerenciamento agrícola moderno, ao invés de ser o resultado final das forças de inovação. Somando-se ao processo de racionalização do trabalho, a seleção dos paraibanos é realizada para reprimir algumas práticas de resistência dos trabalhadores, como o abandono do contrato de safra e algumas ações promovidas pelos sindicatos.

Seguindo as instruções dos gerentes da usina, o arregimentador rejeita documentos de trabalhadores que não se enquadram dentro dos critérios estabelecidos pela usina; os que têm ações na justiça são considerados como aqueles que "dão problema", são "trabalhadores ruins". Ele incorpora o poder atribuído pelos gerentes da usina para rejeitar pessoas que, segundo seu julgamento, não tenham sido cooperativos e produtivos na safra anterior; alguns trabalhadores declaram sua raiva quando o arregimentador nega-se a receber a carteira de trabalho.

Entretanto, o comportamento dos arregimentadores tende a variar, sendo que alguns se posicionam mais do lado dos trabalhadores e outros mais do lado da usina. Esses buscam honrar seu compromisso com os trabalhadores, porque se algo de errado acontecer, poderá afetar sua imagem no espaço de sua moradia, bem como sua posição social como líder dos trabalhadores. Um exemplo disto aconteceu com o recrutamento realizado pela Usina Matari, essa usina é bem conhecida pelas condições de trabalho e moradia precárias. $\mathrm{O}$ arregimentador tentou todos os meios para selecionar 50 trabalhadores, conforme o pedido da usina, mas não conseguiu completar esta quantidade, muitos não entregaram suas carteiras para serem selecionados pela usina e, entre os que foram, muitos desistiram do contrato antes do final da safra. A imagem negativa da usina afetou também a imagem do arregimentador, ele declarou que ficou numa situação constrangedora e embaraçosa porque sentia que havia traído a confiança dos trabalhadores nele.
Embora o arregimentador realize o recrutamento de trabalhadores migrantes através de critérios que visam a um disciplinamento da força de trabalho, tanto para garantir maiores níveis de produtividade quanto para controlar as atitudes de resistência dos trabalhadores e sua relação com o sindicato, ele também se orienta pelas relações de amizade ou parentesco que estabelecem obrigações, dependência, respeito, ajuda mútua entre ele e os camponesestrabalhadores migrantes.

* Marilda Aparecida de Menezes é Prof". do Programa de Pós-Graduação em Sociologial UFPB-Campina Grande.

\section{NOTAS}

1- A hierarquia nas usinas de cana-de-açúcar em Pernambuco apresenta a seguinte estrutura: - Trabalhadores;

- Arregimentador;

- Cabo: é o chefe imediato dos trabalhadores; organiza a distribuição das atividades diárias, mede a produção diária e supervisiona o trabaIho no campo;

- Fiscal: supervisiona uma área de cana-deaçúcar, mede a produção diária e checa a pesagem da cana realizada pelo cabo;

- Administrador: é responsável pelos alojamentos dos trabalhadores migrantes e também supervisiona os trabalhadores no campo. É o chefe do cabo e do fiscal, e mora em casa da usina, que se situa ao lado dos dormitórios dos trabalhadores migrantes;

- Gerentes de campo: controlam a qualidade, a produtividade $\mathrm{e}$ a administração dos diferentes processos da cana-de-açúcar;

- Gerente do setor agrícola: é o gerente geral de todas as atividades do setor agrícola.

2 - Sempre que refiro a outros autores, respeito as conceituações e categorias que eles utilizam para identificar "camponeses - trabalhadores migrantes". No caso, Breman classificaos como "trabalhadores migrantes.

3 - Este dado refere-se ao estado como um todo e não apenas à região canavieira; porém esse setor é o maior empregador de trabalho assalariado agrícola. (Schaffner, 1993, p. 716)

4 - Sigaud também situa o empreiteiro de forma ambígua nas relações de trabalho na plantation açucareira: "Nesse sentido poderse-ia situar cabo e empreiteiro numa categoria também ambígua dentro da classificação dos moradores. O morador vive sua relação com eles como uma relação de exploração, mas 'compreende' (no sentido weberiano) o seu modo de agir" (Sigaud, 1980, p.44).

\section{REFERÊNCIAS BIBLIOGRÁFICAS}

BAUD, $M$.

(1992) 'Sugar and Unfree Labour: Reflections on Labour control in the Dominican Republic, 1870-1935'. Journal of Peasant Studies, Vol. 19, n..2, pp. 301-342.

BREMAN, J.

(1985) Of peasants, migrants and paupers: rural labour circulation and capitalist production in West India. Delhi: Oxford University Press.

BREMAN, J.

(1994) Wage hunters and gatherers; search for work in the urban and rural economy of South Gujarat. Delhi: Oxford University Press. BURAWOY, M.

(1976) 'The functions and reproduction of Migrant Labor: Comparative material from Southern Africa and the United States'. American Journal of Sociology, Vol. 81, No.5, March 1976, pp.1050-1086.

HARRIES, P.

(1994). Work, culture and identity: migrant laborers in Mozambique and South Africa, 1860-1910. Portsmouth: Heinemman, Johannesburg: Witwatersrand University Press.

MAYER, $P$

(1964) Labour migrancy and the social network. In: Holleman, J.F. et al. (eds.) Problems of transition: Proceedings of the social sciences research conference 1962 , pp. 21-34.

MENEZES, M. A. de

(1997) Peasant-Migrant Workers: Social networks and pratices of resistance. Tese de Doutoramento em Ciências Sociais. Manchester, University of Manchester.

MOREIRA, E.R.F. (Coord.)

(1995) Os caras pintadas de suor e de fuligem da cana lum estudo das condiçōes de vida, saúde e trabalho dos trabalhadores mirins da cana]. Relatório Técnico Final de Pesquisa. João Pessoa: Universidade Federal da Paraiba.

NOVAES, J.R.P.

(1993) Modernização e Relação de Poder: transformaçōes na agroindústria canavieira no Nordeste do Brasil. Ph.D. Thesis. Programa em Economia da Universidade Estadual de Campinas.

OLIVEIRA, C.F.G.

(1986) 'O empreiteiro - elemento intermediário na contratação da mão-de-obra volante na zona canavieira Pernambucana'. Cadernos do CEAS, No. 102, pp. 41-53. SIGAUD, L.

(1980). A nação dos homens: uma análise regional de ideologia. In: Anuário Antropológico 78, pg. 13-114.

SCHAFFNER, J.A.

(1993) 'Rural Labor legislation and permanent agricultural employment in Northeastern Brazil'. World Development, Vol. 21, No.5, pp.705-719. 